This document is the Accepted Manuscript version of a Published Work that appeared in final form in Journal of the American Society, copyright (C) American Chemical Society after peer review and technical editing by the publisher. To access the final edited and published work http://pubs.acs.org/doi/abs/10.1021/jacs.5b03955

\title{
Ipso-Borylation of Aryl Ethers via Ni-catalyzed C-OMe Cleavage
}

\author{
Cayetana Zarate, ${ }^{\dagger}$ Rubén Manzano ${ }^{\dagger}$ and Ruben Martin* ${ }^{\dagger \S}$ \\ ${ }^{\dagger}$ Institute of Chemical Research of Catalonia (ICIQ), Av. Països Catalans 16, 43007, Tarragona, Spain \\ ${ }^{\S}$ Catalan Institution for Research and Advanced Studies (ICREA), Passeig Lluïs Companys, 23, 08010, Barcelona, Spain
}

Supporting Information Placeholder

ABSTRACT: A Ni-catalyzed ipso-borylation of aryl ethers via $\mathrm{C}\left(\mathrm{sp}^{2}\right)-\& \mathrm{C}\left(\mathrm{sp}^{3}\right)-\mathrm{OMe}$ cleavage is described. The transformation is characterized by its wide substrate scope under mild conditions and an exquisite divergence in site-selectivity that can be easily switched by an appropriate selection of the boron reagent.

In recent years, $\mathrm{C}-\mathrm{O}$ electrophiles have emerged as powerful alternatives to aryl halides as coupling partners in the cross-coupling arena. ${ }^{1,2}$ While the utilization of activated aryl esters, carbamates or sulfonates has become routine, it comes as a surprise that aryl methyl ethers, the simplest derivatives in the phenol series, have received much less attention. ${ }^{2}$ This is likely due to the high activation energy required for $\mathrm{C}-\mathrm{OMe}$ scission and the low propensity of methoxy residues to act as leaving groups. Not surprisingly, these reactions remain essentially confined to $\mathrm{C}-\mathrm{C}$ bond-formations using highly reactive, well-defined, stoichiometric and, in many cases, air-sensitive organometallic reagents (Scheme 1, path $a) .{ }^{2}$ Intriguingly, a C-heteroatom bond-formation has been virtually unexplored (path $b$ ), ${ }^{3}$ thus constituting a unique opportunity to implement unconventional strategies not apparent at first sight in our chemical portfolio.

\section{Scheme 1. Catalytic C(sp $\left.{ }^{2}\right)$-OMe Bond-Cleavage.}

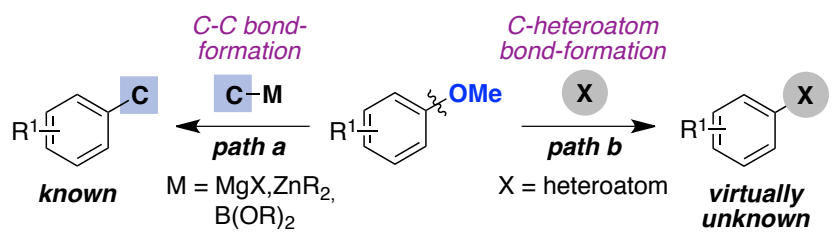

The pivotal role of organoboron reagents as synthetic intermediates has attracted the attention of both industrial and academic laboratories for decades. ${ }^{4}$ Not surprisingly, the recent years have witnessed the development of a myriad of catalytic methods for their synthesis. ${ }^{5-8}$ At present, the inclusion of aryl methyl ethers has merely been employed as a control element for promoting $\mathrm{C}-\mathrm{B}$ bond-forming reactions at either ortho-, meta- or paraposition via ortho-metalation or the intermediacy of aryl halides via electrophilic aromatic substitution (Scheme 2 , path $a),{ }^{9,10}$ or C-H activation (path $\left.b\right){ }^{6}$ From a synthetic standpoint, the ability to promote a complementary ipso-borylation of aryl methyl ethers would be highly rewarding, offering a counterintuitive, yet practical, new retrosynthetic approach to organoborane reagents from simple precursors. ${ }^{11}$ At the outset of our investigations, it was unclear whether such scenario would be feasible given the exceptional inertness of $\mathrm{C}-\mathrm{OMe}$ bonds, ${ }^{2}$ the natural proclivity of aryl ethers to promote functionalization at ortho- or para-positions ${ }^{12}$ and the virtual lack of precedents for $\mathrm{C}$-heteroatom bondformation via $\mathrm{C}-\mathrm{OMe}$ cleavage. ${ }^{3}$ If successful, such a strategy would not only open up new vistas in $\mathrm{C}-\mathrm{B}$ bond-formation but also might represent a significant step-forward for implementing aryl methyl ethers as privileged counterparts in cross-coupling endeavours. ${ }^{2}$ As part of our interest in $\mathrm{C}-\mathrm{O}$ bond-functionalization, ${ }^{13}$ we describe herein the first catalytic ipso-borylation of aryl methyl ethers via $\mathrm{C}\left(\mathrm{sp}^{2}\right)$ - and even $\mathrm{C}\left(\mathrm{sp}^{3}\right)-\mathrm{O}$ cleavage, thus exploiting a previously unrecognized opportunity in this field. ${ }^{14,15}$ This protocol is characterized by its wide scope under mild conditions and by an exquisite 
divergence in site-selectivity that can be modulated by a judicious choice of the corresponding boron reagent.

Scheme 2. Borylation Events of Aryl Methyl Ethers.

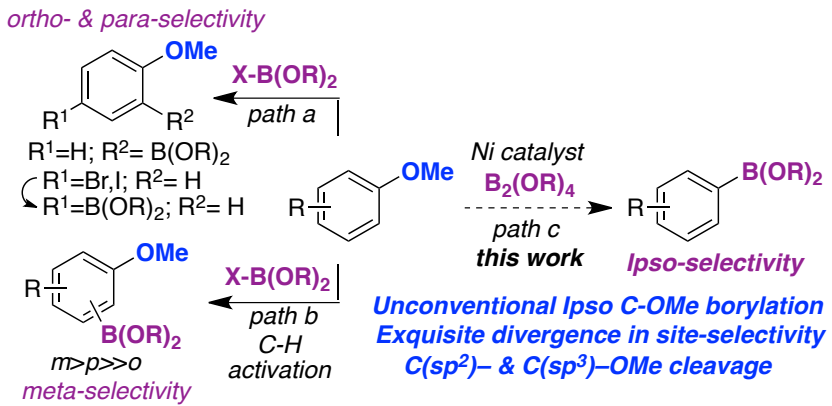

We began our investigations by evaluating the reaction of $1 \mathbf{a}$ with $\mathrm{B}_{2}(\mathrm{nep})_{2}$ (2a). After extensive experimentation, ${ }^{16}$ we found that a cocktail containing $\mathrm{Ni}(\mathrm{COD})_{2}$, $\mathrm{PCy}_{3}$ and $\mathrm{HCO}_{2} \mathrm{Na}$ promoted the targeted reaction at 95 ${ }^{\circ} \mathrm{C}$, affording 3a in $80 \%$ isolated yield. Although $\mathrm{HCO}_{2} \mathrm{Na}$ has commonly been employed as reducing agent in cross-coupling reactions, ${ }^{17}$ marginal formation of naphthalene was detected in the crude mixtures $(<9 \%)$. Interestingly, the utilization of other bases provided inferior results (entries 11 and 12). ${ }^{18}$ As anticipated, the nature of the ligand employed had a profound influence on the reaction outcome (entries 5-7). Strikingly, the inclusion of otherwise related $\mathrm{PCy}_{2} \mathrm{Ph}$ had a deleterious effect on reactivity, thus showing the subtleties of our protocol (entry 5). Similarly, $N$-heterocyclic carbenes provided 3a in lower yields (entries 6 and 7). ${ }^{19}$ Notably, a difference in reactivity was found when operating under a $\mathrm{NiCl}_{2}\left(\mathrm{PCy}_{3}\right)_{2}, \mathrm{Ni}\left(\mathrm{PCy}_{3}\right)_{2}\left(\mathrm{C}_{2} \mathrm{H}_{4}\right)$ or $\left[\mathrm{Ni}\left(\mathrm{PCy}_{3}\right)_{2}\right]_{2} \mathrm{~N}_{2}$ regime (entries 8-10). Although tentative, we believe that COD might be acting as a noninnocent ancillary ligand to stabilize the putative $\mathrm{Ni}\left(\mathrm{PCy}_{3}\right)_{2}$ species and prevent decomposition pathways. ${ }^{20}$ The lack of reactivity of $\mathrm{B}_{2}(\text { pin })_{2}(\mathbf{2} \mathbf{b}$; entry 13 ) is noteworthy, suggesting an intimate interplay between steric effects and productive $\mathrm{C}-\mathrm{B}$ bond-formation. In line with this notion, ethoxy, isopropoxy or benzyloxy groups gave lower conversions to 3a. ${ }^{16}$ As anticipated, control experiments revealed that all reaction parameters were critical for success (entries 2-4). ${ }^{16}$

Table 1. Optimization of the Reaction Conditions. ${ }^{a}$

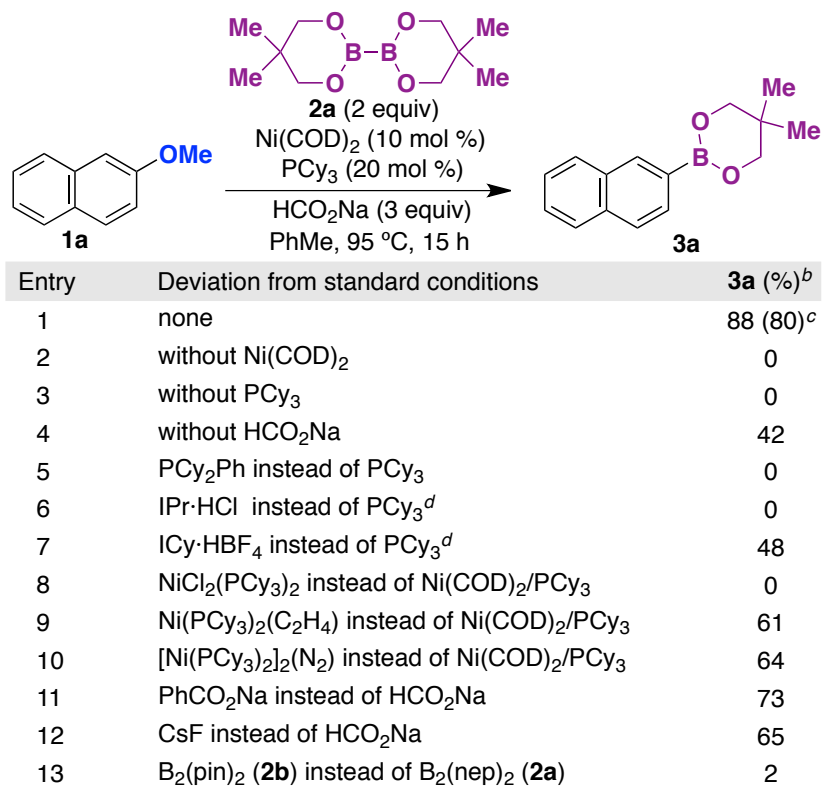

${ }^{a}$ Conditions: 1a $(0.50 \mathrm{mmol}), 2 \mathrm{a}(1.00 \mathrm{mmol}), \mathrm{Ni}(\mathrm{COD})_{2}$ (10 mol\%), $\mathrm{PCy}_{3}(20 \mathrm{~mol} \%), \mathrm{HCO}_{2} \mathrm{Na}(1.50 \mathrm{mmol})$ in PhMe $(2.0 \mathrm{~mL})$ at $95{ }^{\circ} \mathrm{C}, 15 \mathrm{~h} .{ }^{b} \mathrm{GC}$ yields using decane as internal standard. ${ }^{c}$ Isolated yield. ${ }^{d}+\mathrm{NaO} t \mathrm{Bu}(25 \mathrm{~mol} \%)$.

With a reliable procedure in hand, we next turned our attention to explore the preparative scope of our catalytic ipso-borylation technique via $\mathrm{C}\left(\mathrm{sp}^{2}\right)-\mathrm{OMe}$ bondcleavage (Table 2). As shown, a wide variety of naphthyl ethers possessing a diverse set of substitution patterns could perfectly be tolerated, obtaining in all cases good yields of 3a-3k. The chemoselectivity profile of our method was nicely illustrated by the fact that silyl groups (3b), silyl ethers (3e), esters ( $\mathbf{3} \mathbf{f}$ and $\mathbf{3 k}$ ), ketones $(\mathbf{3 g})$ and amines (3i) could all be equally accommodated. Importantly, the presence of nitrogen-containing heterocycles did not interfere with productive $\mathrm{C}-\mathrm{B}$ bondformation (3d and $\mathbf{3 h}$ ). As shown for $\mathbf{3 j}$, the reaction was not hampered by the presence of ortho-substituents. It is worth noting that no racemization of the chiral center in $\mathbf{3 k}$ was observed when exposing enantioenriched $\mathbf{1 k}(96 \%$ ee) under our optimized reaction conditions. Intriguingly, the inclusion of $\mathrm{CsF}$ and $\mathrm{B}_{2} \mathrm{pin}_{2}(\mathbf{2 b})$ cleanly afforded $\mathbf{3 l}$ and $\mathbf{3 m}$ via $\mathrm{C}\left(\mathrm{sp}^{3}\right)-\mathrm{OMe}$ cleavage. ${ }^{21-23}$ Likewise, benzyl methyl ethers posessing $\beta$-hydrogens posed no problems, obtaining $3 \mathbf{n}$ in $81 \%$ yield. ${ }^{24,25}$

Table 2. Ipso-Borylation of Naphthyl Methyl Ethers 


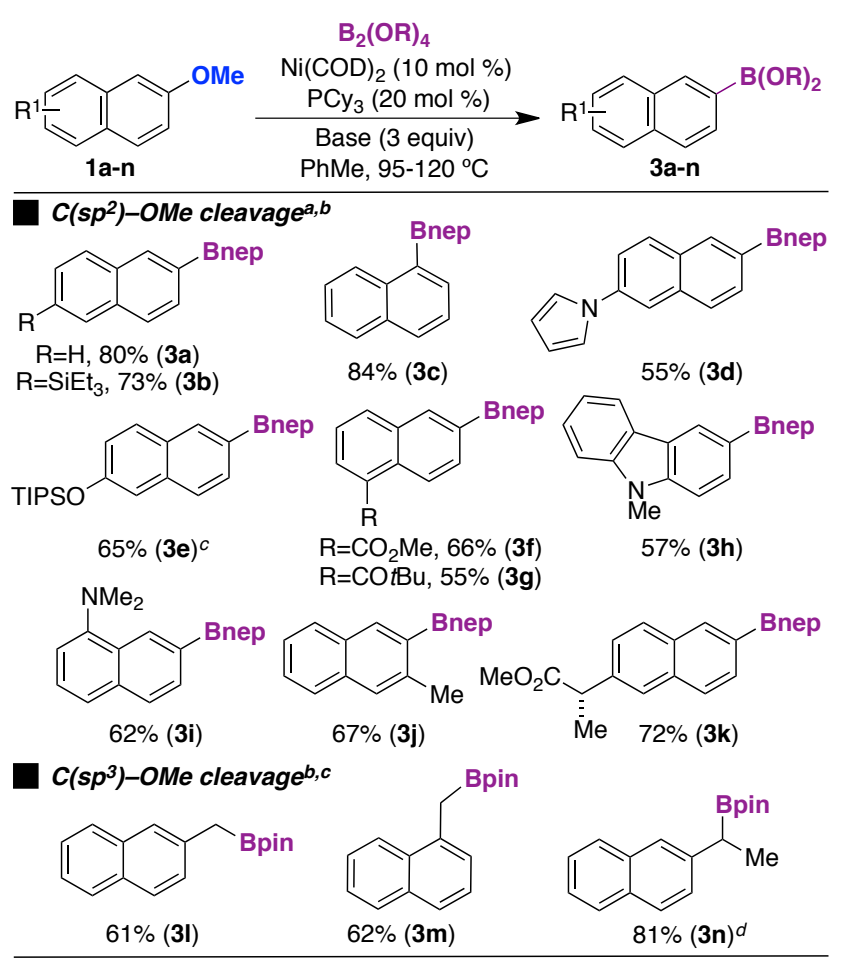

${ }^{a}$ As for Table 1 (entry 1) using $\mathbf{2 a}{ }^{b}$ Isolated yields, average of at least two independent runs. ${ }^{c} 120{ }^{\circ} \mathrm{C}$. ${ }^{d}$ As for Table 1 (entry 1), but employing $2 \mathbf{b}(1.00 \mathrm{mmol})$ and $\mathrm{CsF}$ (1.50 mmol) at $120{ }^{\circ} \mathrm{C}$. ${ }^{d}$ Determined by GC (decane as internal standard). Bnep: 5,5-dimethyl-1,3,2-dioxaborolane; Bpin: 4,4,5,5-tetramethyl-1,3,2-dioxaborolane.

A close inspection into the literature data indicates that regular arenes are several orders of magnitude less reactive than non $\pi$-extended systems in $\mathrm{C}-\mathrm{O}$ bond-cleavage protocols. $^{26,27}$ At present, such lack of reactivity has been overcome primarily by employing stoichiometric and highly reactive organometallic species, ${ }^{1,2}$ thus representing a drawback from a practical and synthetic point of view. In light of these precedents, we wondered whether our Ni-catalyzed ipso-borylation event could be applied to more challenging aryl methyl ethers. Although such scenario proved to be difficult, we speculated that the presence of suitable ortho-substituents might facilitate the elusive $\mathrm{C}-\mathrm{OMe}$ bond-cleavage in anisole derivatives. As shown in Table 3, this was indeed the case for a variety of aryl methyl ethers possessing orthoesters (5a-5c), trifluoromethyl groups (5d) or amides (5e). ${ }^{28,29}$ Importantly, the presence of such groups in para or meta position gave negligible conversion to products, thus providing compelling evidence that electronic effects are not the only factor coming into play. ${ }^{30}$ In contrast to the results of Table 1 (entry 13), we found that $\mathrm{B}_{2}$ (pin) $)_{2}(\mathbf{2 b})$ could be utilized for effecting the $\mathrm{C}\left(\mathrm{sp}^{2}\right)$-OMe bond-cleavage $(\mathbf{5 b}, \mathbf{5 e}){ }^{31}$ As for Table 2, we found that a $\mathrm{C}\left(\mathrm{sp}^{3}\right)-\mathrm{OMe}$ bond-cleavage was within reach $(\mathbf{5 f}$ and $\mathbf{5 g})$.

Table 3. Ipso-Borylation of Aryl Methyl Ethers. ${ }^{a, b}$

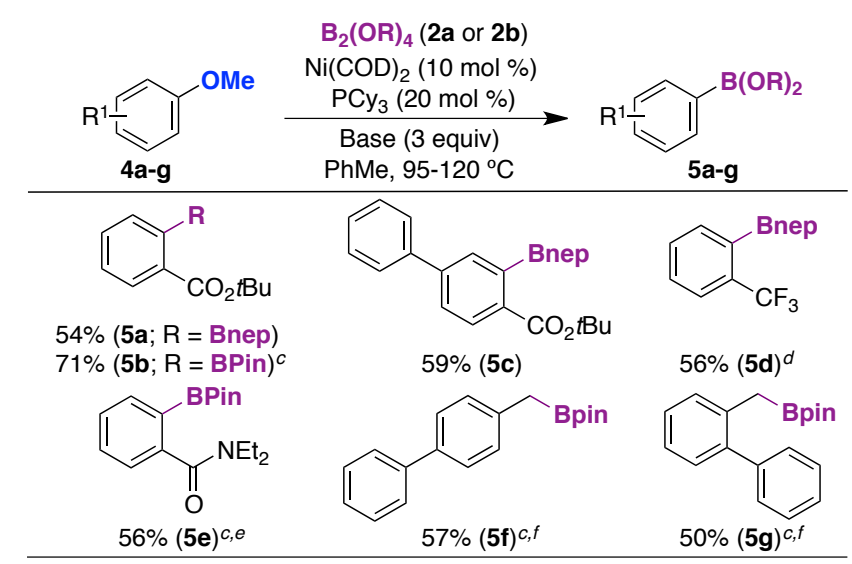

${ }^{a}$ As for Table 1 (entry 1). ${ }^{b}$ Isolated yields, average of at least two independent runs. ${ }^{c}$ Using $2 \mathbf{b}(1.0 \mathrm{mmol}){ }^{d}$ $\mathrm{HCO}_{2} \mathrm{Na}(0.50 \mathrm{mmol}){ }^{e} \mathrm{GC}$ yield using decane as internal standard. ${ }^{f} \mathrm{CsF}(1.00 \mathrm{mmol})$ at $120^{\circ} \mathrm{C}$.

On the basis of the results of Tables 1-3, we concluded that the nature of the boron reagent might not be entirely innocent in the reaction outcome. Challenged by such perception, we speculated that an orthogonal siteselective $C-B$ bond-formation via $\mathrm{C}-\mathrm{OMe}$ bondcleavage could be achieved. To such end, we examined the reactivity of $\mathbf{6 a}$ and $\mathbf{6 b}$ under a $\mathbf{2 a}$ or $\mathbf{2 b}$ regime (Figure 1). Interestingly, while the utilization of $\mathbf{2} \mathbf{b}$ lead exclusively to $7 \mathbf{a}$ and $7 \mathbf{b}$ via $\mathrm{C}\left(\mathrm{sp}^{3}\right)-\mathrm{OMe}$ cleavage, a $\mathrm{C}\left(\mathrm{sp}^{2}\right)-\mathrm{B}$ bond-formation was invariably observed with 2a. ${ }^{32}$ At present, we have no explanation for such intriguing dichotomy. Encouraged by these results, we wondered whether our Ni-catalyzed ipso-borylation could be employed as a manifold to promote an unprecedented ipso-halogenation of aryl methyl ethers, ${ }^{33}$ thus complementing classical ortho- or para-electrophilic aromatic halogenation techniques. ${ }^{34}$ As shown in Figure 1 (bottom), this turned out to be the case and a one-pot borylation/iodination sequence allowed for rapidly obtaining $\mathbf{8 a}$ and $\mathbf{8 b}$ in good overall yield. ${ }^{35}$ Taken together, the results of Tables 2-3 and Figure 1 tacitly suggest that our novel ipso $\mathrm{Ni}$-catalyzed $\mathrm{C}-\mathrm{OMe}$ borylation will foster new explorations in carbon-heteroatom bond-forming reactions via unconventional $\mathrm{C}-\mathrm{O}$ bond-cleavage.

Figure 1. Orthogonal Borylation via C-OMe Cleavage. ${ }^{a, b}$

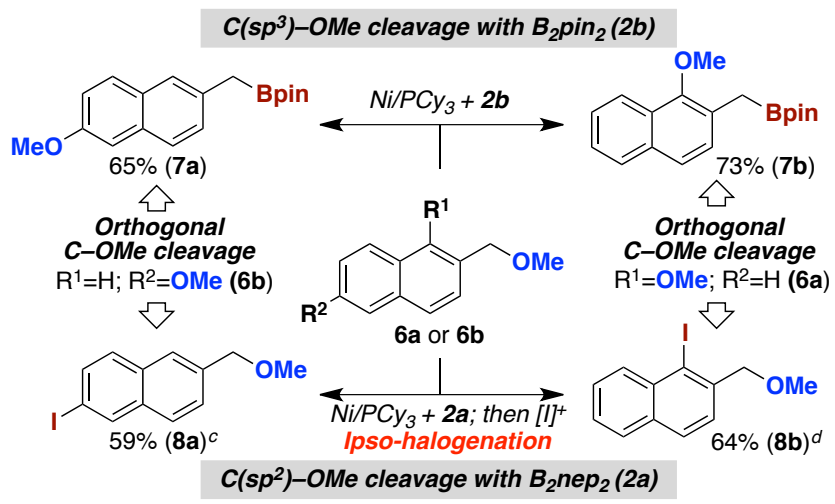


${ }^{a} \mathrm{C}\left(\mathrm{sp}^{3}\right)$-OMe cleavage: $\mathbf{6 a}$ or $\mathbf{6 b}(0.50 \mathrm{mmol}), \mathbf{2 b}(1.00$ $\mathrm{mmol}), \mathrm{Ni}(\mathrm{COD})_{2}(10 \mathrm{~mol} \%), \mathrm{PCy}_{3}(20 \mathrm{~mol} \%), \mathrm{CsF}(1.50$ $\mathrm{mmol})$ in PhMe $(2.0 \mathrm{~mL})$ at $120{ }^{\circ} \mathrm{C} .{ }^{b} \mathrm{C}\left(\mathrm{sp}^{2}\right)-\mathrm{OMe}$ cleavage: as for Table 1 (entry 1$)$, followed by $\mathrm{NaI}(1.50 \mathrm{mmol})$ and chloramine $\mathrm{T} \cdot 3 \mathrm{H}_{2} \mathrm{O}(1.50 \mathrm{mmol})$ in $4 \mathrm{~mL} \mathrm{THF} / \mathrm{H}_{2} \mathrm{O}$ (1:1) at rt. ${ }^{c}$ Borylation conducted at $120{ }^{\circ} \mathrm{C} .{ }^{d}$ Borylation conducted with $\mathrm{HCO}_{2} \mathrm{Na}(0.15 \mathrm{mmol})$

In summary, we have developed the first ipso-borylation of aryl methyl ethers via Ni-catalyzed $\mathrm{C}-\mathrm{OMe}$ bondcleavage, complementing classical ortho-, meta- and para-borylation techniques. This protocol is distinguished by its broad substrate scope and by an intriguing selectivity switch depending on the boron reagent employed. Further investigations into related projects will be reported in due course.

\section{ASSOCIATED CONTENT}

Supporting Information. Experimental procedures and spectral data. This material is available free of charge via the Internet at http://pubs.acs.org.

\section{AUTHOR INFORMATION}

\section{Corresponding Author}

*rmartinromo@iciq.es

\section{Funding Sources}

No competing financial interests have been declared.

\section{ACKNOWLEDGMENT}

We thank ICIQ, the European Research Council (ERC277883), MINECO (CTQ2012-34054 \& Severo Ochoa Excellence Accreditation 2014-2018; SEV-2013-0319) and Cellex Foundation for support. Johnson Matthey, Umicore and Nippon Chemical Industrial are acknowledged for a gift of metal \& ligand sources. C.Z. and R.M. thank MINECO for a FPU and COFUND scholarship.

\section{REFERENCES}

(1) For selected reviews: (a) Tehetena, M.; Garg, N. K. Org. Process Res. Dev. 2013, 17, 129. (b) Yamaguchi, J.; Muto, K.; Itami, K. Eur. J. Org. Chem. 2013, 19. (c) Correa, A.; Cornella, J.; Martin, R. Angew. Chem., Int. Ed. 2013, 52, 1878. (d) Tobisu, M.; Chatani, N. Top. Organomet. Chem. 2013, 44, 35. (e) Rosen, B.M.; Quasdorf, K. W.; Wilson, D. A.; Zhang, N.; Resmerita, A.-M.; Garg, N. K.; Percec, V. Chem. Rev. 2011, 111, 1346. (f) Li, B.-J.; Yu, D.-G.; Sun, C.L.; Shi, Z.-J. Chem. Eur. J. 2011, 17, 1728. (g) Yu, D. -G.; Li, B. -J.; Shi, Z. -J. Acc. Chem. Res. 2010, 43, 1486.

(2) Cornella, J.; Zarate, C.; Martin, R. Chem. Soc. Rev. 2014, 43, 8081.

(3) For the only exception via $\mathrm{C}\left(\mathrm{sp}^{2}\right)-\mathrm{OMe}$ cleavage: (a) Tobisu, M.; Shimasaki, T.; Chatani, N. Chem. Lett. 2009, 38, 710. (b) Tobisu, M.; Yasutome, A.; Yamakawa, K.; Shimasaki, T.; Chatani, N. Tetrahedron 2012, 68, 5157.

(4) (a) Hall, D. G. Boronic Acids; Wiley-VCH: Weinheim, Germany, 2005. (b) Suzuki, A.; Brown, H. C. Organic Synthesis via Boranes; Aldrich: Milwaukee, WI, 2003.

(5) For selected borylation of aryl halides using diboron or hydroboron reagents: (a) Uematsu, R.; Yamamoto, E.; Maeda, S.; Ito, H. J. Am. Chem. Soc. 2015, 137 4090. (b)
Molander, G. A.; Trice, S. L. J.; Dreher, S. D. J. Am. Chem. Soc., 2010, 132, 17701. (c) Moldoveanu, C.; Wilson, D. A.; Wilson, C. J.; Leowanawat, P.; Resmerita, A.-M.; Liu, C.; Rosen, B. M.; Percec, V. J. Org. Chem. 2010, 75, 5438. (d) Zhu, W.; Ma, D. Org. Lett. 2005, 8, 261. (e) Ishiyama, T.; Miyaura, N. Chem. Rec. 2004, 3, 271, and citations therein.

(6) For selected reviews on metal-catalyzed $\mathrm{C}-\mathrm{H}$ borylation: (a) Ros, A.; Fernández, R.; Lassaletta, J. M. Chem. Soc. Rev. 2014, 43, 3229. (b) Hartwig, J. F. Chem. Soc. Rev. 2011, 40, 1992. (c) Mkhalid, I. A. I.; Barnard, J. H.; Marder, T. B.; Murphy, J. M.; Hartwig, J. F. Chem. Rev. 2010, 110, 890. (d) Miyaura, N. Bull. Chem. Soc. Jpn. 2008, 81, 1535.

(7) For catalytic borylations of $\mathrm{C}-\mathrm{CN}$ and $\mathrm{C}-\mathrm{NR}_{2}$ bonds: (a) Tobisu, M.; Kinuta, H.; Kita, Y.; Rémond, E.; Chatani, N. J. Am. Chem. Soc. 2012, 134, 115. (b) Tobisu, M.; Nakamura, K.; Chatani, N. J. Am. Chem. Soc. 2014, 136, 5587.

(8) For synthetic pathways based on transmetallation events from RLi or RMgBr: Brown, H. C.; Cole, T. E. Organometallics 1983, 2, 1316.

(9) (a) Snieckus, V. Chem. Rev. 1990, 90, 879. (b) Hartung, C. G.; Snieckus, V. In Modern Arene Chemistry; Astruc, D., Ed.; Wiley-VCH: Weinheim, Germany, 2002; pp 330-367

(10) (a) Taylor, R. Electrophilic Aromatic Substitutions; WileyVCH: Weinheim, Germany, 1990. For selected electrophilic aromatic borylations: (b) Niu, L.; Yang, H.; Wang, R.; Fu, H. Org. Lett. 2012, 14, 2618. (c) Del Grosso, A.; Pritchard, R. G.; Muryn, C. A; Ingleson, M. J. Organometallics 2010, 29, 241. (d) Muetterties, E. L. J. Am. Chem. Soc. 1960, 82, 4163.

(11) For selected catalytic borylation of particularly activated aryl C-O electrophiles, see: (a) Kinuta, H.; Hasegawa, J.; Tobisu, M.; Chatani, N. Chem. Lett. 2015, 44, 366 (pivalates). (b) Huang, K.; Yu, D. -G.; Zheng, S. -F.; Wu, Z. -H.; Shi, Z. -J. Chem. -Eur. J. 2011, 17, 786 (carbamates). (c) Chow, W. K.; So, C. M.; Lau, C. P.; Kwong, F. Y. Chem. -Eur. J. 2011, 17, 6913 (mesylates \& tosylates). (d) Wilson, D. A.; Wilson, C. J.; Moldoveanu, C.; Resmerita, A.-M.; Corcoran, P.; Hoang, L. M.; Rosen, B. M.; Percec, V. J. Am. Chem. Soc. 2010, 132, 1800 (mesylates \& tosylates).

(12) Klumpp, G. W. Reactivity in Organic Chemistry; Wiley: New York, 1982; pp 227-378.

(13) (a) Zarate, C.; Martin, R. J. Am. Chem. Soc. 2014, 136, 2236. (b) Liu, Y.; Cornella, J.; Martin, R. J. Am. Chem. Soc. 2014, 136, 11212. (c) Moragas, T.; Cornella, J.; Martin, R. J. Am. Chem. Soc. 2014, 136, 17702. (d) Correa, A.; Martin, R. J. Am. Chem. Soc. 2014, 136, 7253. (e) Cornella, J.; Martin, R. Org. Lett. 2013, 15, 6298. (f) Cornella, J.; Gómez-Bengoa, E.; Martin, R. J. Am. Chem. Soc. 2013, 135, 1997. (g) Barbero, N.; Martin, R. Org. Lett. 2012, 14, 796. (h) ÁlvarezBercedo, R.; Martin, R. J. Am. Chem. Soc. 2010, 132, 17352.

(14) While this paper was under preparation, an elegant Rhcatalyzed $\mathrm{C}-\mathrm{B}$ bond-formation of activated aryl ethers decorated with a O-pyridyl group has been described: Kinuta, $\mathrm{H}$.; Tobisu, M.; Chatani, N. J. Am. Chem. Soc. 2015, 137, 1593.

(15) The lack of reactivity of $\mathrm{C}-\mathrm{OMe}$ bonds is clearly illustrated in a recent $\mathrm{C}-\mathrm{H}$ borylation in which $7 \%$ of $\mathrm{C}-\mathrm{OMe}$ borylation was observed: Furukawa, T.; Tobisu, M.; Chatani, N. Chem. Commun. 2015, 51, 6508.

(16) See Supporting information for details.

(17) Diederich, F.; de Meijere, A., Eds. Metal-Catalyzed CrossCoupling Reactions; Wiley-VCH: Weinheim, 2004.

(18) For an elegant structural work on the use of additives for activating B-B bonds: Pietsch' S.; Neeve, E. C.; Apperley, D. C.; Bertermann, R.; Mo, F.; Qiu. D.; Cheung, M. S.; Dang, Li,; Wang, J.;Radius, U.; Lin, Z.; Kleeberg, C.; Marder, T. B. Chem. Eur. J. 2015, 21, 7082.

(19) For the use of NHC in C-OMe cleavage: (a) Tobisu, M.; Yasutome, A.; Kinuta, H.; Nakamura, K.; Chatani, N. Org. 
Lett. 2014, 16, 5572. (b) Tobisu, M.; Morioka, T.; Ohtsuki, A.; Chatani, N. Chem. Sci. 2015, DOI 10.1039/C5SC00305a.

(20) See for example: (a) Fürstner, A.; Majima, K.; Martin, R.; Krause, H.; Kattnig, E.; Goddard, R.; Lehmann, W. J. Am. Chem. Soc. 2008, 130, 1992. (b) ref. 13f.

(21) For selected $\mathrm{C}\left(\mathrm{sp}^{3}\right)-\mathrm{B}$ bond-forming reactions of activated benzyl C-O electrophiles: (a) Matthew, S. C.; Glasspoole, B. W.; Eisenberger, P.; Crudden, C. M. J. Am. Chem. Soc. 2014, 136, 5828. (b) Nave, S.; Sonawane, R. P.; Elford, T. G.; Agarwall, V. K. J. Am. Chem. Soc. 2010, 132, 17096.

(22) No reaction took place in the absence of $\mathrm{Ni}(\mathrm{COD})_{2} / \mathrm{PCy}_{3}$.

(23) Although $\mathrm{B}_{2}(\text { nep })_{2}$ could be utilized as coupling partner, we found that the resulting benzyl neopentylboronates were rather unstable, thus preventing their isolation in pure form.

(24) For selected recent catalytic borylation of alkyl halides possessing $\beta$-hydrogens: (a) Atack, T. C.; Lecker, R. M.; Cook, S. P. J. Am. Chem. Soc. 2014, 136, 9521. (b) Bose, S. K.; Fucke, K.; Liu, L.; Steel, P. G.; Marder, T. B. Angew. Chem. Int. Ed. 2014, 53, 1799. (c) Dudnik, A. S.; Fu, G. C. J. Am. Chem. Soc., 2012, 134, 10693. (d) Joshi-Pangu, A.; Ma, X.; Diane, M.; Iqbal, S.; Kribs, R. J.; Huang, R.; Wang, C. -Y.; Biscoe, M. R. J. Org. Chem. 2012, 77, 6629.

(25) Racemization occurred with enantioenriched 1n, an observation that is tentatively attributed to bimolecular-type mechanisms. For a related scenario, see: Yonova, I. M.; Johnson, A. G.; Osborne, C. A.; Moore, C. E.; Morrissette, N. S.; Jarvo, E. R. Angew. Chem. Int. Ed. 2014, 53, 2422.

(26) For selected $\mathrm{C}-\mathrm{O}$ bond-cleavage procedures in which the presence of $\pi$-extended systems was required: (a) Wisniewska, H. M.; Swift, E. C.; Jarvo, E. R. J. Am. Chem. Soc. 2013, 135, 9083. (b) Zhou, Q.; Srinivas, H. D.; Dasgupta, S.; Watson, M. P. J. Am. Chem. Soc. 2013, 135, 3307. (c) Taylor, B. L.; Harris, M. R.; Jarvo, E. R. Angew. Chem., Int. Ed. 2012, 51, 7790. (d) Yu, D.-G.; Shi, Z.-J. Angew. Chem., Int. Ed. 2011, 50, 7097. (e) Yu, D. G.; Li, B. J.; Zheng, S. F.; Guan, B. T.; Wang, B. Q.; Shi, Z. J. Angew. Chem. Int. Ed. 2010, 49, 4566. (f) Tobisu, M.; Shimasaki, T.; Chatani, N. Angew. Chem., Int. Ed. 2008, 47, 4866, and citations therein.

(27) $\pi$-Extended systems are known to bind stronger than regular arenes low valent metal complexes in a $\eta^{2}$-fashion, probably due to the retention of a certain degree of aromaticity: Bauer, D. J.; Krueher, C. Inorg. Chem. 1977, 16, 884. Alternatively, $\pi$-extended systems might generate easier Meisenheimer-type complexes (ref. 23f) or scenarios dealing with the intermediacy of dearomatized products (ref. 13f)

(28) No C-B bond-formation was found when utilizing electrondonating dimethylamino groups in ortho-position. For the utilization of other anisole derivatives, see ref. 16.

(29) In sharp contrast with the utilization of ortho tert-butyl esters, we found that ortho methyl esters provided lower yields ( $\sim 25 \%$ GC yields), thus revealing an intimate interplay between steric effects and $\mathrm{C}-\mathrm{B}$ bond-formation.

(30) No biaryl formation via Suzuki-Miyaura coupling of in situ generated aryl boronates with aryl ethers was observed.

(31) Intriguingly, while 5e was cleanly obtained with $\mathrm{B}_{2} \mathrm{pin}_{2}$, an otherwise related reaction with $\mathrm{B}_{2}$ (nep) $)_{2}$ did not result in productive $\mathrm{C}-\mathrm{B}$ bond-formation.

(32) Unreacted starting material and marginal reduction of $\mathrm{C}$ OMe bond account for the mass balance.

(33) For halogenation of in situ generated aryl boronates, see for example: (a) Shi, H.; Babinski, D. J.; Ritter, T. J. Am. Chem. Soc. 2015, 137, 3775. (b) Murphy, J. M.; Liao, X.; Hartwig, J. F. J. Am. Chem. Soc. 2007, 129, 15434.

(34) Bew, S. P. In Comprehensive Organic Functional Group Transformations II; Eds., Katritzky, A. R.; Taylor, R. J. K. Elsevier, Oxford, 2005.
(35) The isolation of the corresponding aryl neopentyl boronates was particularly cumbersome due to the instability of the boronic esters during purification by column chromatography. 
Catalytic Ipso Borylation of Aryl Methyl Ethers
via C-OMe Cleavage

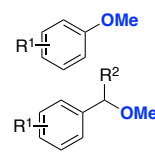
$\mathrm{B}_{2}(\text { nep })_{2}$ or $\mathrm{B}_{2}(\text { pin })_{2}$ Ni catalyst

${ }_{R}^{1} \frac{11}{1}{ }_{R^{2}}^{B n e p}$

$\mathrm{PhMe}, 95^{\circ} \mathrm{C}$

Unconventional Ipso C-OMe borylation

Exquisite divergence in site-selectivity

$c\left(s p^{2}\right)$ - \& $C\left(s p^{3}\right)$-OMe cleavage

Bpin ए 25 examples
up to $81 \%$ yield 